\title{
Nutrition Intervention, Oral Supplementation and Healing of Leg Ulcer in Adult with Sickle Cell Disease: A Rare Case Report
}

\author{
Débora Frauches ${ }^{1}$, Julia da Silva Gonçalves dos Santos ${ }^{1,2}$, Renata Lanziani', \\ Águeda Glória Sabino de Matos' ${ }^{1}$, André Baima1, Ana Maria Mach Queiroz', \\ Eleonora D'Ávila Thomé1, Karen Cordovil1,2
}

\author{
${ }^{1}$ Department of Clinical Hematology, State Institute of Hematology Arthur de Siqueira Cavalcanti (HEMORIO), Rio de Janeiro, \\ Brazil \\ ${ }^{2}$ Oswaldo Cruz Foundation (Fiocruz), Rio de Janeiro, Brazil \\ Email: frauchesster@gmail.com, juliasg.santos@gmail.com,karensouz@gmail.com
}

How to cite this paper: Frauches, D., da Silva Gonçalves dos Santos, J., Lanziani, R., de Matos, Á.G.S., Baima, A., Queiroz, A.M.M., Thomé, E.D. and Cordovil, K. (2020) Nutrition Intervention, Oral Supplementation and Healing of Leg Ulcer in Adult with Sickle Cell Disease: A Rare Case Report. Open Access Library Journal, 7: e6478. https://doi.org/10.4236/oalib.1106478

Received: May 28, 2020

Accepted: July 24, 2020

Published: July 27, 2020

Copyright () 2020 by author(s) and Open Access Library Inc.

This work is licensed under the Creative Commons Attribution International License (CC BY 4.0).

http://creativecommons.org/licenses/by/4.0/

\begin{abstract}
Leg ulcers (LU) are one of the most frequent complications in individuals with sickle cell disease (SCD). Old reports and unofficial documents found at the Nutrition Outpatient Clinic in a reference center for hematological diseases (NOC/RCHD) describe the use of oral supplement (OS) hypercaloric, hyper protein and arginine-rich (OS/HHA) for the healing of leg ulcers. The aim is to describe a rare case of a patient with sickle cell disease and leg ulcer submitted a dietetics orientations and intervention with OS/HHA. A 31-year-old male patient had been performing clinical treatment of sickle cell disease genotype SS for eight years at the RCHD of Rio de Janeiro. He had a unilateral ulcer on his right ankle for about six years, performing dressings by a Nursing team. He started follow-up at the NOC, being classified as grade III malnutrition. 13 nutrition consultations were performed during the study and $10 \mathrm{nu}-$ tritional intervention consultations were carried out offering an OS/HHA containing $6 \mathrm{~g} /$ day of arginine, twice daily for 80 days. For ethical reasons, the participant was informed about the case report, agreeing and signing the consent form and the authorized image use term. Based on the analysis of food intake during the intervention period, energy consumption was on average $2.706 \mathrm{Kcal}$, including OS/HHA. Leg ulcers were found with regular margins and macerated in some areas, an ulcerated lesion with adherent and purulent exudate with $80 \%$ adherent thickness and in large quantities on the $1^{\text {st }}$ day of supplementation. After eighty days, the lesion had regular margins and epithelial tissue, an ulcerative bed with $100 \%$ granulation, tissue and scarce exudate, showing improvement in healing. The patient presented an improvement in the nutritional status and leg ulcer healing. It is necessary to
\end{abstract}


perform experimental research to corroborate or not the results observed in this rare case report.

\section{Subject Areas}

Nursing, Nutrition

\section{Keywords}

Sickle Cell Anemia, Leg Ulcer, Malnutrition, Oral Nutritional Supplementation, Arginine

\section{Introduction}

Leg ulcer (LU) is a secondary complication of sickle cell disease (SCD), usually responsible for increased costs of health services, therapeutic processes or long-term hospitalizations, often caused by the debilitating condition generated to affected patients [1] [2] [3].

Worldwide estimates point to a prevalence of sickle leg ulcer around $27 \%$ in Nigeria, 20\% in Brazil and less than 1\% in the Arabian Peninsula [4] [5] [6]. The incidence of LU in individuals with SCD may be up to ten times higher than in the general population [7]. These ulcers can occur between 10 - 30 years of age and among adults, their incidence can increase from $23.4 \%$ between $18-40$ years to $50 \%$ in adults over 40 years of age [3] [4] [8]. A recent Brazilian study confirmed that $\mathrm{LU}$ is uncommon in children, generally affecting adults more frequently [9].

Regarding the genotype, a cohort study identified the incidence of LU from about $22 \%$ of individuals with homozygotic hemoglobin S (HbSS) and only $9 \%$ with the HbSC genotype [10]. According to Soya et al. (2019), risk factors for the development of LU in SCD are homozygotic hemoglobin S (HbSS), age over 20 years, male, hemoglobin rate below $6 \mathrm{~g} / \mathrm{L}$ and deficiency of antithrombin [11].

LU may appear spontaneously, due to minor trauma or tissue hypoxia due to constant vas occlusion and, appearing in the lower limbs, usually in the malleolar region, where there is thin skin, scarcity of subcutaneous fat and low blood flow [5] [12] [13] [14]. It is healing usually presents with a high recurrence rate, responding worse to treatment than ulcers of other etiologies [5] [14] [15].

As described in the current literature, tissue repair of a wound needs nutrients to promote healing, and the substrate is provided by the diet or the body itself [16].

Patients with the HbSS genotype are generally more predisposed to a higher risk of low weight, possibly caused by the presence of a higher metabolism [17] [18] [19]. Thus, the existence of a chronic wound could probably be another contributing factor to increased energy expenditure [20] so nutritional intervention should be considered as an adjuvant therapeutic measure for LU healing in SCD [21] [22].

International intervention studies have signaled what would be the possible 
benefits of using nutritional supplements in chronic wounds, including LU in SCD [21] [22]. Among the main nutrients used in supplementation to optimize, healing would be protein-rich, RGD peptide matrix and arginine, a semi-essential amino acid involved in the endothelial production of nitric oxide in blood vessels [21] [22] [23] [24].

In Hemorio, old reports and unofficial documents found at the Nutrition Outpatient Clinic describe the use of oral supplement hypercaloric, hyper-protein and arginine-rich (OS/HHA) for the treatment and healing of $\mathrm{LU}$ in patients with SCD. In these unofficial reports, the nutritionist observed that, after the introduction of OS/HHA, the patients presented significant body mass gain and, consequently, improvement in malnutrition. According to unofficial reports of some patients, after using OS for some months, they showed improvement in pain, increased appetite, improved healing process and greater willingness to perform day-to-day tasks.

Considering what was described above, the importance of nutritional care of adult patients with SCD and LU, and the limited availability of studies in this area in Brazil, there was interest in describing a rare case report of a patient with SCD and LU, accompanied by a multidisciplinary team of a reference center for SCD, where nutritional interventions and hyper-protein and hyper-caloric supplementation containing arginine were performed.

\section{Case Report}

The data were collected in the period from April to July 2017, from consultations carried out by a multiprofessional team composed of hematologists, dermatologists, plastic surgeons, nursing and nutrition teams. All the professionals were connected during the study period to the Arthur de Siqueira Cavalcanti Institute of Hematology (Hemorio) outpatient clinic, located in the city of Rio de Janeiro, which belongs to the state of Rio de Janeiro, Brazil.

There were 13 Nutrition consultations during the study period, among them 10 nutritional intervention consultations. The information was collected from the unit's medical records and from specific reports of the Nutrition in Hematology team.

For ethical reasons, the patient was informed about the study and accepted to participate in it by signing the Free and Informed Consent Term (FICT) and the Image Use Authorization Term (IUAT). As this was a study linked to the Clinical Nutrition Program of the State Institute of Hematology Arthur Siqueira Cavalcanti (Hemorio), it was analyzed and approved by the Hemorio Scientific Committee in July 2018.

This is a male patient, 31 years of age, black race, possessing the first complete degree and with a diagnosis of SCD at 3 months of age. He began treatment/follow-up at the Hemorio at 23 years of age. Patient reported as main complaint the presence of unilateral ankle ulcer for about 6 years.

During the study period (April to July 2017), besides being accompanied by 
the hematologist and the multiprofessional team, the patient performed hyper transfusion periodically every 15 days or once a month according to the clinical procedures in the hospital unit hemotherapy.

During consultations with the hematologist, the following medications were prescribed: analgesic (Dipyrone), opioid (Codeine), non-steroidal anti-inflammatory (Ibuprofen), antidepressant (Amitriptyline), proton pump inhibitor (Omeprazole) and folic acid. There were no reports of use of the Hydrea drug during the study period.

The patient was constantly changing dressings in the Nursing Service for the treatment of an ulcerated lesion in the right medial malleolus and also received nutritional guidance in the Nutrition Outpatient Clinic, however, still without the use of any type of nutritional supplementation, because there was no availability of nutritional supplements in the sector at that time.

In April 2017, the Hemorio Nutrition and Dietetics Service received an anonymous donation of about 160 bottles of hyper-protein, hyper-caloric oral supplement containing arginine (Table 1). These nutritional supplements were sent to the Nutrition Outpatient Clinic for nutritional intervention to a patient who at the time did not present renal and/or liver complications. The absence of these two complications made the choice of this case possible.

From that, the monitoring was performed with the Nutrition team at the $\mathrm{Nu}$ trition and Dietetics Department of the Hemorio. In the first consultation (April $24,2017)$ the general information necessary for the patient to receive the supplementation was verified and anthropometric measures for monitoring the nutritional status were performed.

In general, in all consultations, the nutritionist was observed through the medical chart, follow-up with the multiprofessional team and laboratory tests. Anthropometric measures and food consumption evaluation were also performed, as well as nutritional guidelines and systematic monitoring of the proposed nutritional supplement use, to identify the evolution of the patient's nutritional status.

To prepare the case report, information regarding consultation with the multiprofessional team, clinical data, nutritional intervention and nutritional supplementation were collected from the patient's hospital records.

During the study period, the following laboratory data were collected: hemoglobin (g/dl), hematocrit (\%), mean corpuscular volume (MCV), mean corpuscular hemoglobin $(\mathrm{MCH})$, mean corpuscular hemoglobin concentration (MCHC), leukocytes $\left(\mathrm{mil} / \mathrm{mm}^{3}\right)$, lymphocytes $\left(\mathrm{mil} / \mathrm{mm}^{3}\right)$ neutrophils $\left(\mathrm{mil} / \mathrm{mm}^{3}\right)$ and platelets $\left(\mathrm{mil} / \mathrm{mm}^{3}\right)$.

Anthropometric data were collected in the first, sixth and tenth consultations following with the body reserves data, only available on these dates in the patient's physical chart.

Body mass $(\mathrm{BM})$ and height $(\mathrm{H})$ were measured in the patient to follow the evolution of the nutritional status during the use of nutritional supplementation. The body mass index (BMI) was determined according to the Quetelet formula 
Table 1. Nutritional composition of the arginine-rich supplement offered by 80 days to a patient with a sickle cell disease HbSS to aid in leg ulcer healing in Rio de Janeiro, Brazil, 2017.

\begin{tabular}{|c|c|c|}
\hline Variable & Amount per $200 \mathrm{ml}$ & $\%$ RDI \\
\hline \multicolumn{3}{|l|}{ Energy } \\
\hline Total, Kcal & 250 & - \\
\hline Proteins, \% & 30 & - \\
\hline Carbohydrates, \% & 45 & - \\
\hline Fats, $\%$ & 25 & - \\
\hline \multicolumn{3}{|l|}{ Macronutrients } \\
\hline Proteins, $\mathrm{g}$ & 20 & 40 \\
\hline Carbohydrates, g & 28 & - \\
\hline Fats, $g$ & 7 & - \\
\hline \multicolumn{3}{|l|}{ Minerals } \\
\hline Calcium, $\boldsymbol{m g}$ & 450 & 45 \\
\hline Iron, $m g$ & 6 & 43 \\
\hline Sodium, $m g$ & 100 & - \\
\hline Potassium, $m g$ & 300 & - \\
\hline Chlorine, $m g$ & 160 & - \\
\hline Phosphorus, $m g$ & 364 & 52 \\
\hline Magnesium, $m g$ & 84 & 32 \\
\hline Zinc, $m g$ & 9 & 128 \\
\hline Copper, $m c g$ & 1350 & 150 \\
\hline Manganese, $m g$ & 2.5 & 109 \\
\hline Fluoride, $\boldsymbol{m g}$ & 0.38 & 10 \\
\hline Molybdenum, $m c g$ & 38 & 83 \\
\hline Selenium, $m c g$ & 64 & 188 \\
\hline Chromium, $m c g$ & 25 & 71 \\
\hline Iodine, $m c g$ & 50 & 38 \\
\hline \multicolumn{3}{|l|}{ Vitamins } \\
\hline Vitamin A, $m c g$ RE & 32 & 25 \\
\hline Carotenoides, $\boldsymbol{m g}$ & 1.5 & - \\
\hline Vitamin D, mcg & 2.6 & 52 \\
\hline Vitamin E ( $\alpha$-tocopherol), $m g$ & 38 & 380 \\
\hline Vitamin $\mathrm{K}, \mathrm{mcg}$ & 20 & 31 \\
\hline Thiamin, $m g$ & 0.56 & 47 \\
\hline Riboflavin, $m g$ & 1.27 & 97 \\
\hline Niacin, $m g$ & 6.8 & 42 \\
\hline Pantothenicacid, $m g$ & 2 & 40 \\
\hline Vitamin $\mathrm{B}_{6}, \mathrm{mg}$ & 1.3 & 100 \\
\hline Folicacid, $m g$ & 200 & 83 \\
\hline Vitamin $\mathrm{B}_{12}, \boldsymbol{m g}$ & 1.6 & 66 \\
\hline Biotin, $m g$ & 15 & 50 \\
\hline Vitamin C, $\boldsymbol{m g}$ & 250 & 555 \\
\hline Choline, $m g$ & 138 & 25 \\
\hline
\end{tabular}

Acronym: Recommended daily intake for adults (RDI). 
$\left(\mathrm{BM} / \mathrm{H}^{2}\right)$ and evaluated based on the cut points recommended by the World Health Organization [25] [26] [27]. The mid-upper arm circumference (MUAC) and triceps skinfold (TK) were also measured. The arm muscle area (AMA) was calculated using the formula: AMA $(\mathrm{cm})=\{\operatorname{MUAC}(\mathrm{cm})-[3.14 \times(\mathrm{TK}(\mathrm{mm}) \div$ 10)] $\}$ [28]. The percentage of adequacy of MUAC, TK and AMA were classified according to Blackburn and Thornton [29].

All the data collected from the patient were typed, consolidated in Excel Spreadsheet (Office Microsoft ${ }^{\circledR} 2010$ ) and represented through tables and graphs. Descriptive statistics (mean and standard deviation) were calculated for biochemical and anthropometric indicators.

The evaluation of calorie and nutrient intake was performed through a record of usual consumption (zero time, TZ) performed in the first Nutrition consultation in April and three 24-hour recalls, applied on non-consecutive days and randomly during the eighty days of the study. At usual consumption (TZ), the patient was guided to report in detail the food normally consumed, and information was collected on the typology, quantities consumed (portion size), frequency of consumption, number of daily meals, form of preparation and location of meals. The patient was oriented to respond on the food and beverages consumed throughout the previous day and the respective quantities, being reported in the form of home measurements, separately, starting at breakfast until dinner. The patient was also encouraged to report the consumption of snacks, biscuits, sweets, soft drinks as well as the use of oil, salt and sugar for the preparation of meals.

In the food consumption analysis, the quality of the information collected was checked and the conversion of food and beverages into grams and milliliters, respectively, was performed. Three food composition tables [26] [30] [31] were used to obtain the available amounts of calories and nutrients. In the case of industrialized foods, information from the product label itself was used.

In the evaluation of habitual consumption (TZ), the patient had four meals a day (breakfast, lunch, snack and dinner) characterized by large spaces between them. Among a total of 2871 calories consumed, the patient's diet was hyper glycidic, hyper proteinic and normolipidemic. Also, low consumption of fruits, vegetables and greens were observed ( 4 times a week) as well as, there was a predominance of the consumption of foods with high sodium content ( $133 \%$ of the RDA), saturated fat ( $92 \%$ of the total fat) and simple carbohydrates (52\% of the total carbohydrates). Thus, specific nutritional guidelines for the SCD and qualitative guidelines were given.

During the consultations with the nutritionist, the patient received qualitative nutritional guidelines, such as: 1) increasing the consumption of fruits, vegetables and greens; 2) adding olive oil to the main meals to increase energy consumption; 3) not skipping meals; 4) avoiding excessive consumption of ultra-processed foods. The patient had already received qualitative guidelines in nutritional consultations before the study and supplementation.

In addition to the nutritional guidelines and to promote healing, a specific 
oral supplement (OS) enriched with arginine was provided to the patient to be consumed twice a day, for approximately three weeks (80 days). Each $200 \mathrm{ml}$ portion of the OS provides $250 \mathrm{kcal}$ and 20 grams of protein, which corresponds to $40 \%$ of the daily recommendation. Also, the OS provides vitamins and minerals involved in healing, in addition to folic acid and iron (Table 1). During the study period, the patient had no renal and/or hepatic complications that made it impossible for him to receive the supplementation rich in arginine.

From the food consumption data, the total energy value (TEV), macronutrients (carbohydrate, protein and lipid), arginine, the micronutrients most involved in healing (vitamin A, vitamin C, vitamin E, selenium and zinc) and iron were analyzed.

The energy requirement was calculated at the beginning of the study by multiplying the resting energy expenditure (Harris-Benedict equation) with a correction factor of 1.2 for physical activity and a stress factor of 1.1 [32] [33].

Daily carbohydrate and lipid requirements were calculated according to Dietary Reference Intakes (DRI's), where carbohydrate intake should be $45 \%$ - 65\% and lipid intake should be $20 \%-35 \%$ of total caloric value [34] [35].

Daily protein requirements were established for a bodyweight intake of 1.5 $\mathrm{g} / \mathrm{kg}$, and adjustments were based on The National Pressure Ulcer Advisory Panel and European Pressure Ulcer Advisory Panel guidelines [36]. The recommended doses for supplementation of arginine considering age and sex would be around 4.5 to $9 \mathrm{~g} /$ day [21] [35] [37] [38].

The prevalence of adequate micronutrient intake was estimated by sex and age group (Men; 31 - 50 years), using the Estimated Average Requirement (EAR) method as a cutoff bridge, as proposed by the Institute of Medicine [39] [40].

Data on patient food consumption were consolidated in the Microsoft Excel $^{\circledR}$ application, version 2010. Mean and standard deviation was calculated for each nutrient separately, with percentages from $90 \%$ to $110 \%$ considered adequate.

\section{Comments}

We present a rare case report of a patient with SCD and LU accompanied by a multidisciplinary team of a reference center for SCD where nutritional interventions and hyper-protein and hyper-caloric supplementation containing arginine were performed.

The nutritional care of patients with SCD is essential, since these individuals may present nutritional deficiencies that may impact their nutritional status in a progressively and chronically [41] [42]. Secondary complications related to the presence of sickle cell may contribute to the increase of metabolic and energetic demand. Therefore, a nutritional intervention should be performed to reach individual needs and keep body mass within normal limits [43].

As previously mentioned, a multiprofessional assistance accompanied a 31year-old patient with $\mathrm{Hb}$ SS who had had leg ulcers on his right ankle for about 6 
years. It was observed that, when performing a nutritional intervention based on nutritional guidelines and protein-calorie supplementation rich in arginine (Table 1) for a period for 80 days, there was wound regression. At the end of the 80 days the nutritional supplement donated was over and one week later the patient reported that the ulcer opened again.

\section{Laboratory Parameters}

The laboratory and anthropometric characteristics of the patient before, during and after the intervention with oral supplementation were compiled in Table 2. Generally, patients with SCD and LU may exhibit low hemoglobin values and relatively higher leukocyte and platelet counts compared to patients without LU [44].

In this report, it was observed that serum hemoglobin, erythrocyte and hematocrit levels in all stages of the study were significantly lower than the recommended values, corroborating that observed in the current literature [11] [44]. The leukocyte and lymphocyte levels were high at all stages of the study, confirming our findings.

Table 2. Laboratory and anthropometric characteristics before, during and after the nutrition intervention and oral supplementation of an adult patient with sickle cell disease Hb SS and leg ulcers in Rio de Janeiro, Brazil, 2017.

\begin{tabular}{cccccc}
\hline AD & Baseline & During & After & Mean $( \pm$ SD $)$ & REF \\
\hline Hemoglobin, g/dL & 7.85 & 7.40 & 6.70 & $7.32( \pm 0.58)$ & $12.8-17.8$ \\
ERYT, milhões/mm ${ }^{3}$ & 2.53 & 2.48 & 2.17 & $2.39( \pm 0.20)$ & $4.50-6.10$ \\
Hematocrit, \% & 22.5 & 22.5 & 18.9 & $21.30( \pm 2.08)$ & $39-53$ \\
MCV, fl & 88.8 & 90.9 & 87.0 & $88.90( \pm 1.95)$ & $80-98$ \\
MCH, pg & 31.0 & 29.9 & 30.8 & $30.57( \pm 0.59)$ & $25-32$ \\
MCHC, g/dl & 35.0 & 32.9 & 35.5 & $34.47( \pm 1.38)$ & $32-36$ \\
LEU, mil/mm ${ }^{3}$ & 20.200 & 24.900 & 25.500 & $23.53( \pm 2.90)$ & $3.600-11.000$ \\
LYMP, mil/mm ${ }^{3}$ & 11.000 & 14.700 & 15.800 & $13.83( \pm 2.51)$ & $1.000-4.500$ \\
NEU, mil/mm ${ }^{3}$ & 6.930 & 7.500 & 6.700 & $7.04( \pm 0.41)$ & $1.500-7.000$ \\
PLA, mil/mm ${ }^{3}$ & 531 & 345 & 343 & $406.33( \pm 107.97)$ & $140-360$ \\
Weight, Kg & 51.5 & 53.0 & 53.8 & $52.8( \pm 1.17)$ & - \\
BMI, Kg/m ${ }^{2}$ & 16.4 & 16.9 & 17.2 & $16.8( \pm 0.37)$ & $18.5-24.9$ \\
TCF, mm & 4.0 & 6.0 & 6.0 & $5.3( \pm 1.15)$ & 12.0 \\
AC, cm & 23.1 & 25.0 & 25.5 & $24.5( \pm 1.27)$ & 31.9 \\
AMC, cm & 21.8 & 23.1 & 23.6 & $22.9( \pm 0.92)$ & 27.9 \\
\hline
\end{tabular}

Notes: Baseline: first-time referral where the nutritional supplement was prescribed in April 2017; During: consult the query in one month in May 2017; After: refers to the last consultation with the use of the nutritional supplement in July 2017. The results were published by automated machines with the optical reader. For the calculation of the body mass was considered the height of $1.77 \mathrm{~m}$ of the patient. Anthropometric data were classified according to a reference to the World Health Organization (27), Frisancho (28) and Reis and Blackburn (29). Acronyms: standard deviation (SD), laboratory reference (REF), erythrocytes (ERYT), mean corpuscular volume (MCV), mean corpuscular hemoglobin (MCH), mean corpuscular hemoglobin concentration (MCHC), Lymphocytes (LYMP), Neutrophils (NEU), Leukocyte (LEU), Platelets (PLA), body mass index (BMI), Tricipital cuff fold (TCF), Arm Circumference (AC), Arm Muscular Circumference (AMC). 
The patient's serum platelet level was high before the intervention, but within normal values during and after the nutritional intervention. In the SCD, elevated platelet serum levels are usually related to the pathogenesis of vaso-occlusive events and may not be directly associated with the occurrence of LU [4] [44] [45] [46] [47] [48].

\section{Patient's Nutritional Status}

In adults with SCD, it is common to observe chronic malnutrition that can be associated with osteopenia and evolve to sarcopenia when there is no intervention in time [45] [46] [47] [48]. Regarding anthropometric measurements, it was observed that before the nutritional intervention, the patient was classified with grade III leanness and throughout the follow-up he obtained weight gain in body mass (about $2.3 \mathrm{~kg}$ ), increase in MUAC and AMA evolving to the condition of thinness grade II.

Patients with SCD may present nutritional disorders caused by high metabolic demand and protein turnover, endocrine dysfunction, low dietary intake, altered metabolic pathways and nutrient malabsorption [41] [43] [49] [50].

Figure 1 shows the evolution of the adequacy of body reserves before, during and after nutritional intervention with OS. It was observed that, after the introduction of OS, the patient presented an improvement mainly in the muscle reserve, going from moderate to mild malnutrition. Despite this, he maintained severe depletion of the fat reserve.

The scientific literature shows that there are three possible causes to explain this event: 1) suppression of appetite for inflammatory mediators; 2) chronic hemolysis would lead to changes in body composition, through a relative increase in visceral fat-free mass and inflammation; 3) chronic inflammation

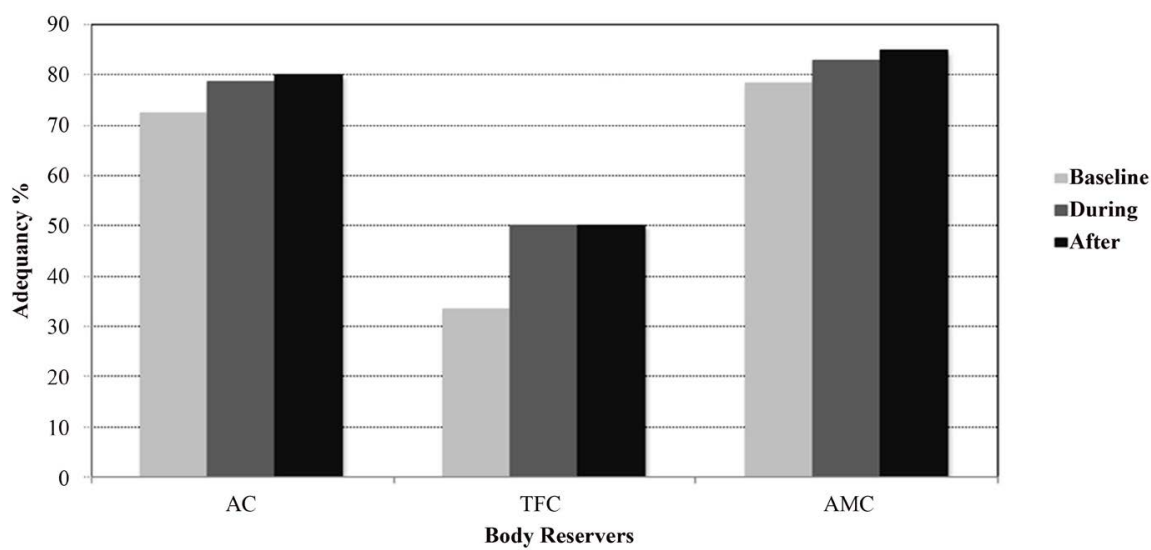

Figure 1. Evolution of the adequacy of body reserves before, during and after nutritional intervention with oral supplementation in an adult of 31 years with sickle cell disease HbSS and leg ulcer in Rio de Janeiro, Brazil, 2017. Notes: Baseline: first-time referral where the nutritional supplement was prescribed in April 2017; During: consult the query in one month in May 2017; After: refers to the last consultation with the use of the nutritional supplement in July 2017. Adequacy data were obtained according to the classification of Frisancho (28) and Reis \& Blackburn (29). Acronyms: Tricipital cuff fold (TCF), Arm Circumference (AC), Arm Muscular Circumference (AMC). 
would probably be associated with increased cytokines, such as tumor necrosis factor-alpha (TNF- $\alpha$ ) and interleukin-6 (IL-6), which would inhibit leptin and insulin, thus contributing to relative hypophagia, lower fat mass and thinness [43].

In contrast, the inflammation reduction by a hyper protein diet in a study on weaning in Berkeley models of sickle cell mice was associated with an improved rate of weight gain, supporting the theory that relative hypophagia is related to high inflammatory mediators [51].

\section{Dietetic Consumption}

The patient's food consumption was evaluated quantitatively through four 24-hour recalls, one performed before intervention with OS (called zero timeZT) and another three during the $20^{\circ}, 60^{\circ}$ and $80^{\circ}$ days with nutritional supplementation. It was calculated about total calories, carbohydrate, protein and total fats. The absolute values, means, standard deviations and recommendations are represented in Table 3.

It was observed that at zero time $(\mathrm{ZT})$ characterized by habitual consumption before the OS prescription, calories (energy), protein and carbohydrates were above the recommendations, while the adequacy of total dietary fat was below the recommendation. During the nutritional intervention, the calories remained high, but the protein and fat adequacy were within the recommendations for the patient.

However, it is important to note that these observations were made through general recommendations for healthy individuals. The patient with SCD and chronic ulcer may have very high nutritional demands, and there is still a shortage of studies that can evaluate the true caloric, protein and micronutrient needs.

Hyacinth (2010) considers that the increased need for macronutrients for $\mathrm{Hb}$

Table 3. Dietary intake of macronutrients on nutrition intervention and oral supplementation of an adult patient with sickle cell disease Hb SS and leg ulcers in Rio de Janeiro, Brazil, 2017.

\begin{tabular}{cccccccc}
\hline Daily Intake, units & ZT & 20 DWS & 60 DWS & 80 DWS & Mean & SD & RCM \\
\hline Energy, Kcal & 2871 & 2550.6 & 2347.1 & 3221.5 & 2706.4 & 457.5 & $1912.4^{32}$ \\
Protein, g/Kg & 2.64 & 2.15 & 1.68 & 2.26 & 2.0 & 0.3 & $1.5^{36}$ \\
Protein, \% & 18.9 & 17.4 & 14.78 & 14.48 & 15.6 & 1.6 & $10-35^{34}$ \\
Carbohydrate, \% & 68.1 & 58 & 64.7 & 54.2 & 59.0 & 5.3 & $45-65^{34}$ \\
Total Fat ,\% & 15.9 & 24.7 & 20.7 & 27.46 & 24.3 & 3.4 & $20-35^{34}$
\end{tabular}

Note: To adjust the percentage of protein, carbohydrate and total fat, the following percentages were used, individually calculated for the patient: $17 \%$ for protein; $59 \%$ for carbohydrate and $25 \%$ for total fat. Mean, SD and RCM were calculated for the three food recalls. Acronyms: usual intakes performed without the prescription of supplementation, called zero time (ZD), 24-hour dietary recalls questionnaire (24 hDR): Twenty days with supplementation (20 DWS); Sixty days with supplementation (60 DWS); Eighty days with supplementation (80 DWS), Standard deviation (SD), Recommendation (RCM) of total energy value calculated using the Harris-Benedict Equation (32), daily protein requirements based on the National Pressure Ulcer Advisory Panel and European Pressure Ulcer Advisory Panel guidelines (36), acceptable macronutrient distribution ranges (AMDR) for protein, carbohydrate and total fat (34). 
SS patients is possibly too high to be simply provided by the diet, as these patients usually suffer anorexia due to a general chronic malaise. But first, specific dietary requirements for these patients should be established [52].

In general, proteins develop an important role in the whole healing process, both in the inflammatory phase, through the proliferative phase to the remodeling phase, because they are used as substrate and as inflammatory mediators (proteolytic enzymes, cytokines and neuropeptides) throughout the process. Also, insufficient energetic input causes protein depletion, since the protein reserves function as an energetic source leading to the loss of lean mass [16].

\section{Consumption of Micronutrients}

The dietary intake of important micronutrients in healing, such as vitamin A, vitamin $\mathrm{C}$, vitamin $\mathrm{E}$, selenium and zinc, in addition to iron and folic acid were evaluated in Table 4. For comparison, the Estimated Average Requirement (EAR), which is the Dietary Reference Intake (DRI) indicated to make a quantitative estimate of the usual adequacy of a nutrient by a healthy individual or populations [53] [54] [55], was used. Recommended Dietary Intake (RDA) is most commonly used for individual dietary planning.

An increase in the suitability of all micronutrients, including iron, was observed. The average iron consumption during the intervention period was about $22 \mathrm{mg}$ per day and its suitability reached $373 \%$ according to EAR recommendations of $6 \mathrm{mg}$ per day.

Patients with SCD present a tendency to iron overload, either through excess iron released by constant hemolysis (increasing oxidative stress), or through chronic transfusions in which these patients are usually submitted [56] [57].

In the cross-sectional study of Antwi-Boasiako et al. (2019), patients with

Table 4. Requirements, intake mean, standard deviation and adequacy intake for micronutrients with estimated average requirement values established of an adult patient with sickle cell disease and leg ulcers in Rio de Janeiro, Brazil, 2019.

\begin{tabular}{cccccccc}
\hline Element & EAR $^{*}$ & RDA $^{* *}$ & 20 DWS & 60 DWS & 80 DWS & Mean & SD \\
\hline Vitamin A, $\mu \mathrm{g}$ & 625 & 900 & 662 & 706 & 700 & 689.3 & 23.9 \\
Vitamin C, mg & 75 & 90 & 525 & 731.3 & 624.5 & 626.9 & 103.2 \\
Vitamin E, mg & 12 & 15 & 79 & 83.6 & 87.9 & 83.5 & 4.5 \\
Folic Acid, $\mu \mathrm{g}$ & 320 & 400 & 901.7 & 561.6 & 940.6 & 801.3 & 208.5 \\
Iron, mg & 6 & 8 & 22 & 20.5 & 24.7 & 22.4 & 2.1 \\
Selenium, $\mu \mathrm{g}$ & 45 & 55 & 294.8 & 186.9 & 198.5 & 226.7 & 59.2 \\
Zinc, mg & 9.4 & 11 & 34 & 23.6 & 26.9 & 28.2 & 5.3 \\
\hline
\end{tabular}

Note: These calculations refer only to micronutrients from the diet. The patient performed transfusion sessions periodically which could increase the body iron status. The micronutrients present in the table are those that have a beneficial action in the wound healing process. Iron has been selected, especially to identify its quantitative dietary intake, since patients with sickle cell disease are advised to consume minimal amounts of this micronutrient. The patient also used a folic acid supplement. Acronyms: Daily micronutrient intake was evaluated at 20,60 and 80 days with supplementation (DWS); ${ }^{\star}$ Estimated Average Requirements (EAR) and ${ }^{* *}$ Recommended Daily Allowance (RDA) (mg/day/ or $\mu \mathrm{g} /$ day) according to established recommendation ranges (mg/day/ or $\mu \mathrm{g}$ /day) 31 - 50 years (39); Standard deviation (SD). 
HbSS had high plasma iron levels compared to controls, and may have been explained by the severe intravascular hemolysis observed in these patients [58]. Therefore, the supplement offered to the patient was not the most appropriate, however, it was not possible to obtain an arginine-based supplement that could be iron-free.

\section{Evolution of UP}

Figure 2 shows the clinical evolution of the LU before, during and after OS consumption. According to the report of the Nursing team, in the first evaluation without supplementation (ZT), the malleolar ulcer was found with regular and macerated margins in some areas, and ulcerated lesion with $80 \%$ of thick sphacel adhered and purulent exudate in large quantities.

On the 20th day of supplementation, the ulcer had adhered margins, an ulcerated lesion with $70 \%$ granulation tissue, and a moderate amount of purulent exudate. On the 60th day, the ulcer showed a significant evolutionary improvement with an apparent decrease in the lesion diameter. On the 80th day, the lesion already had regular margins and epithelialization tissue, an ulcerated lesion with $100 \%$ granulation tissue, and scarce exudate, showing a significant improvement in the ulcer aspect.

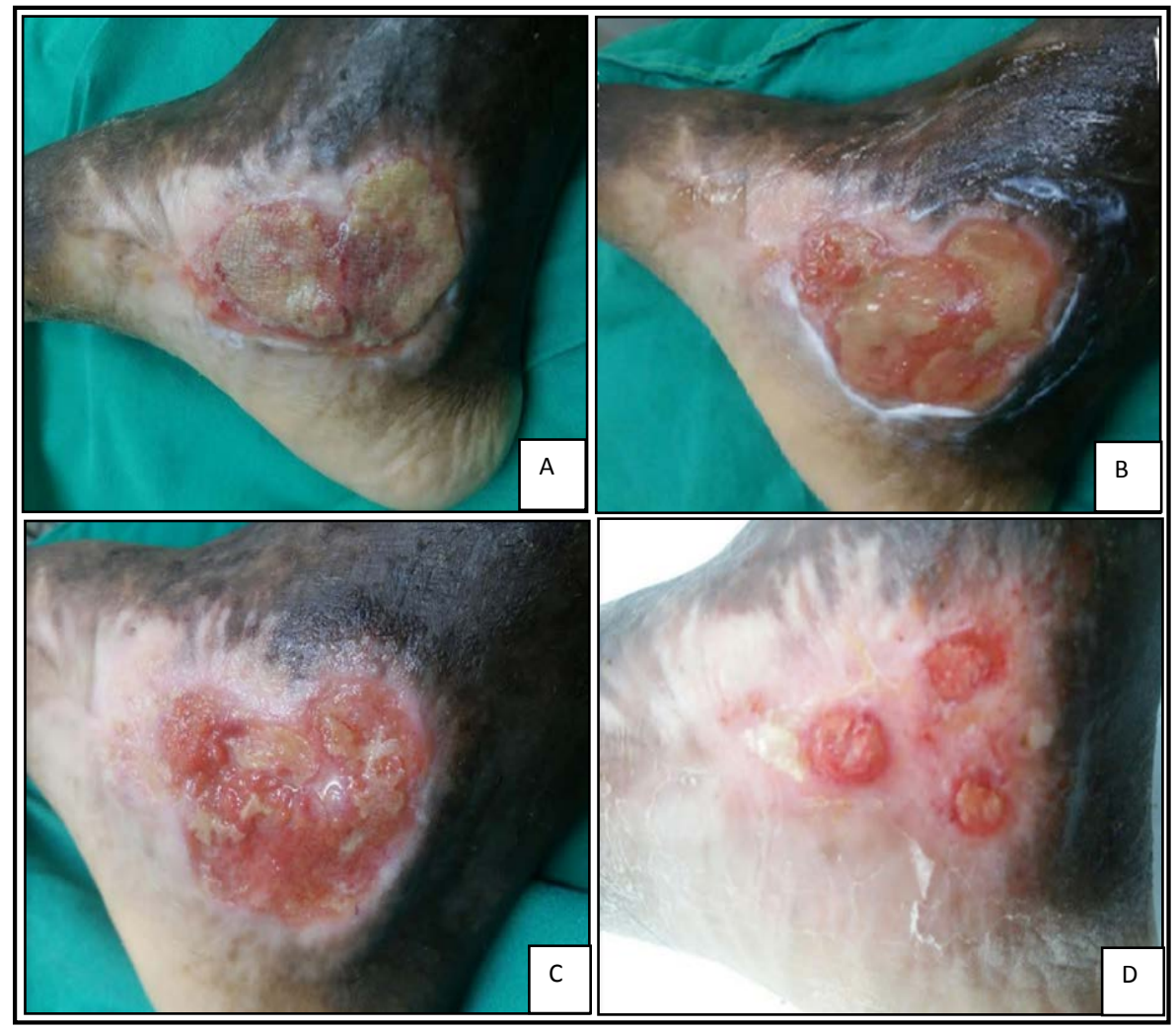

Figure 2. Clinical evolution of leg ulcer during oral nutritional supplementation of an adult patient with sickle cell disease HbSS in Rio de Janeiro, Brazil, 2017. Acronyms: Leg ulcer on the first assessment day in the zero time (A) Twenty days leg ulcer with the use of supplementation (B), Sixty-day leg ulcer with the use of nutritional supplementation (C), Leg ulcer in eighty days with the use of supplementation (D). 
Additionally, the increased consumption of food sources of arginine, zinc, selenium, vitamin $\mathrm{A}$, vitamin $\mathrm{C}$, vitamin $\mathrm{E}$ was also concomitant with the clinical course and healing of the ulcer during the study period. Thus, these micronutrients may have contributed positively to the improvement of the ulcer picture for several reasons.

\section{Arginine and leg ulcer}

The supplement used in this study has different characteristics such as the presence of arginine. Arginine is a semi-essential amino acid in humans, abundantly present in seafood, nuts, seeds, meats and soy protein isolate, so supplementation in the diet of healthy adults is not necessary [59]. Despite the high availability of arginine in the diet, the rate at which it is used or metabolized can influence the bioavailability of this amino acid, which can lead to deficiency conditions with possible clinical implications [60] [61] [62].

This reduction in the bioavailability of arginine has been reported in many conditions of acute or chronic physiological stress [61] [63], where the main mechanism seems to be the diversion of pathways for the production of other inflammatory substances or excessive production of nitric oxide (NO) also as part of an exacerbated inflammatory response [64] [65].

In diseases that are observed high rates of hemolysis, it is believed that the consumption of arginine's stocks by increased arginase activity occurs [66]. In high concentrations, this enzyme reduces plasma arginine, which is the only substrate of endothelial nitric oxide synthase, thus decreasing the NO production. According to this state of NO deficiency, patients with SCD who present higher rates of hemolysis tend to have more frequent complications related to endothelial dysfunction, among them leg ulcers [66] [67].

Arginine is also important to promote protein synthesis, cell division, the release of growth hormone and stimulates the responsiveness of $\mathrm{T}$ cells, helping to prevent infections [68] [69]. Also, as an important precursor to NO, it has been proposed that arginine supplementation can help in wound healing, increasing NO production [69] acting as an important vasodilator and attractive chemo of monocytes, neutrophils and various cytokines (such as IL-1 and TGF- $\beta$ ) during the acute phase of the wound healing process [70] [71].

An open multicenter study including 245 patients, analyzed the evolution of pressure ulcers using the same supplement used in the present study. After nine weeks of nutritional support, the mean pressure ulcer area reduced significantly. Complete healing of the wound occurred after three and nine weeks in $7 \%$ and $20 \%$, respectively [72]. In the multicenter, randomized, controlled and blind study by Cereda et al. [73], it was evaluated whether a hypercaloric, hyper protein oral supplement enriched with arginine, zinc and antioxidants, improves the healing of pressure ulcers in 200 malnourished adult patients. It was observed that, after 8 weeks of intervention with the OS, there was a significant reduction in the ulcer area when compared to the controls.

Clinical interventions that take into account the use of arginine supplements should be further studied to be applied in clinical practice, and that not only 
measures such as dressings and medications help in the treatment of ulcer.

\section{Multiprofessional Team's Performance}

LU is one of the most frequent complications of SCD, associated with enormous physical and psychosocial discomfort, due to their chronicity and considerable recurrence rate [5] [74]. Therefore, a multiprofessional approach is needed that considers self-care practices, better treatment compliance and quality of life maintenance in patients with chronic ulcers.

In this case report, the management of patients with LU had the integrated performance of a multiprofessional team of specialists in SCD and LU, and this was essential for the provision of comprehensive care at the SCD. Generally, the hematologist is responsible for coordinating, managing and providing direct care to patients with SCD and LU [3]. Other health professionals, whether they are doctors or not, support the demands generated by hematologists and their patients.

The clinical nutritionist in a reference center for patients with SCD, is a professional who provides matrix support to the hematologist doctor and to all multiprofessional team. For the nutritionist, the great challenge in working in hematology is to be recognized as a professional capable of dealing with all the specificity of the SCD. The frequent demands always focus on changes in the nutritional status, secondary complications of the disease and nutritional deficiencies. In the case of LU, the diet should be prescribed in detail by an experienced nutritionist, since a positive nitrogen balance is essential for proper collagen formation and healing improvement [3] [75].

Findings, Recommendations and Limitations of the Study

This case report had the possibility of demonstrating interesting results in the use of nutritional supplements recommended for patients with SCD and LU. Such findings could be further explored, tested and proven through the establishment of intervention and/or case-control research that could study a population of patients with LU and the relationship with the use of hypercaloric and hyper-protein nutritional supplements rich in arginine.

The limiting factors in this case report were: 1) supplementation that included iron in the composition, which could cause iron overload; 2) unavailability of some tests during follow-up and intervention with supplementation, such as fetal hemoglobin $(\mathrm{FH})$, lactate dehydrogenase $(\mathrm{LDH})$, erythrocyte sedimentation rate, reticulocytes, ferritin, and iron; 3 ) the hospital received a donation of supplements made by employees, former patients, patients' relatives and anonymous persons; however, during one period of the study, the stock of donations ended and the patient was without the supplement, which consequently predisposed him to reopen the LU.

We did not see any side effects. What could happen is an increase in iron, but laboratory data were not available.

\section{Conclusions}

Our results showed that the hyper protein and hypercaloric supplementation 
containing arginine acted in a positive way collaborating to the healing of the leg ulcer, in the improvement of the nutritional state and especially in the muscular reserve of the patient. During the follow-up, the increase in caloric consumption was observed, as well as an increase in the consumption of micronutrients important for healing.

The main limitation of the study was the lack of supplements needed to maintain supplementation until complete ulcer healing. Unfortunately, the wound expanded again after discontinuation of nutritional supplementation treatment.

Due to the complexity of the physiopathology of LU in SCD, it is essential to have a multiprofessional team to provide integral care to the demands of the individual and optimize the treatment and healing of LU.

The clinical nutritionist performs the differentiated matrix support to the hematologist and the whole team. He has an important role to foster attitudes that will lead the patient to follow an adequate diet, which benefits the healing process and minimizes factors that act hindering this process.

Clinical trials using supplements rich in arginine could contribute to confirm the potential for LU healing in individuals with SCD.

\section{Acknowledgements and Contributions}

DF e JG contributed all the cases to the study, wrote, reviewed, and edited the manuscript; AGSM was responsible for nursing care; $\mathrm{AB}$ and ET were responsible for medical leg ulcer care; AM responsible for hematology care; RL contributed with nutritional care and coordinated of study. KC coordinates all case reports including writing, proofreading, and student orientation for manuscript writing.

The authors thank HEMORIO's dressing committee, scientific committee, study center and nutrition service.

\section{Conflicts of Interest}

The authors report no conflicts of interest.

\section{References}

[1] Anvisa (2002) Manual for the Diagnosis and Treatment of Sickle Cell Disease. National Health Surveillance Agency, Brasília.

[2] Alencar, S.S., et al. (2015) Most Prevalent Clinical Complications in Patients with Sickle Cell Disease from a Medium-Sized Town in Minas Gerais, Brazil. Revista Médica de Minas Gerais, 25, 88-98. https://doi.org/10.5935/2238-3182.20150032

[3] Minniti, C.P. and Kato, G.J. (2016) Critical Reviews: How We Treat Sickle Cell Patients with Leg Ulcers: How We Treat Patients with SCD and Leg Ulcers. American Journal of Hematology, 91, 22-30. https://doi.org/10.1002/ajh.24134

[4] Madu, A.J., et al. (2013) Evaluation of Clinical and Laboratory Correlates of Sickle Leg Ulcers: Sickle Leg Ulcer. Wound Repair and Regeneration, 21, 808-812. https://doi.org/10.1111/wrr.12100

[5] Brazil (2012) Sickle Cell Disease: Ulcers: Prevention and Treatment. Ministry of Health, Brasília. 
[6] Alsultan, A., et al. (2014) Sickle Cell Disease in Saudi Arabia: The Phenotype in Adults with the Arab-Indian Haplotype Is Not Benign. British Journal of Haematology, 164, 597-604. https://doi.org/10.1111/bjh.12650

[7] Sen, C.K., et al. (2009) Human Skin Wounds: A Major and Snowballing Threat to Public Health and the Economy. Wound Repair and Regeneration, 17, 763-771. https://doi.org/10.1111/j.1524-475X.2009.00543.x

[8] Belini Junior, E., Silva, D.G.H., Torres, L.S., Okumura, J.V., Lobo, C.L.C. and Bonini-Domingos, C.R. (2015) Severity of Brazilian Sickle Cell Disease Patients: Severity Scores and Feasibility of the Bayesian Network Model Use. Blood Cells, Molecules and Diseases, 54, 321-327. https://doi.org/10.1016/j.bcmd.2015.01.011

[9] Carneiro-Proietti, A.B.F., Kelly, S., Miranda Teixeira, C., Sabino, E.C., Alencar, C.S., Capuani, L., et al. (2018) Clinical and Genetic Ancestry Profile of a Large Multi-Centre Sickle Cell Disease Cohort in Brazil. British Journal of Haematology, 182, 895-908. https://doi.org/10.1111/bjh.15462

[10] Minniti, C.P., Taylor, J.G., Hildesheim, M., O’Neal, P., Wilson, J., Castro, O., et al. (2011) Laboratory and Echocardiography Markers in Sickle Cell Patients with Leg Ulcers. American Journal of Hematology, 86, 705-708. https://doi.org/10.1002/ajh.22065

[11] Soya, E., Makowski, C. and Blaise, S. (2019) Leg Ulcer Induced by Hydroxycarbamide in Sickle Cell Disease: What Is the Therapeutic Impact? International Wound Journal, 16, 897-902. https://doi.org/10.1111/iwj.13115

[12] Kendall, C. (2018) Sickle Cell Leg Ulcers: A Case Study. Plastic Surgical Nursing, 38, 99-100. https://doi.org/10.1097/PSN.0000000000000226

[13] Bowers, A.S., Reid, H.L., Greenidge, A., Landis, C. and Reid, M. (2013) Blood Viscosity and the Expression of Inflammatory and Adhesion Markers in Homozygous Sickle Cell Disease Subjects with Chronic Leg Ulcers. PLoS ONE, 8, e68929. https://doi.org/10.1371/journal.pone.0068929

[14] El Khatib, A. and Hayek, S. (2016) Leg Ulcers in Sickle Cell Patients: Management Challenges. Chronic Wound Care Management and Research, 3, 157-161. https://doi.org/10.2147/CWCMR.S85455

[15] Altman, I.A., Kleinfelder, R.E., Quigley, J.G., Ennis, W.J. and Minniti, C.P. (2016) A Treatment Algorithm to Identify Therapeutic Approaches for Leg Ulcers in Patients with Sickle Cell Disease: Treatment Algorithm for Sickle Cell Ulcers. International Wound Journal, 13, 1315-1324. https://doi.org/10.1111/iwj.12522

[16] Montenegro, S. (2012) Protein and Wound Healing. Revista Noticias, 14, 27-30.

[17] Aminu, T.M., Adegoke, S.H., Muhammad, I.B., Abdulwasi'u, A., Baba, S.B. and Pwavimbo, A.J. (2017) Antioxidant Vitamins A and E in Relation to BMI in Steady State Sickle Cell Anaemia and Normal Controls in North Eastern Nigeria.

[18] Chawla, A., Sprinz, P.G., Welch, J., Heeney, M., Usmani, N., Pashankar, F., et al. (2013) Weight Status of Children with Sickle Cell Disease. Pediatrics, 131, e1168-e1173. https://doi.org/10.1542/peds.2012-2225

[19] Kaufman, K., Chin, S.-H., Kahathuduwa, C., Wood, M., Feliu, M., Hill, L., et al. (2018) BMI, Psychosocial Correlates, Pain and Activities of Daily Living in Sickle Cell Disease Patients. Progress in Preventive Medicine, 3, e0019. https://doi.org/10.1097/pp9.0000000000000019

[20] Vasconcelos, C.M.A.F., Damasceno, C.V.X. and Silva, V.M. (2017) Arginine Recommendation in Nutritional Therapy for Burn Patients: Current Aspects. Revista Brasileira de Queimaduras, 16, 194-199.

[21] Neyens, J., Cereda, E., Rozsos, I., Molnar, A., Rondas, A., van Leen, M., et al. (2017) 
Effects of an Arginine-Enriched Oral Nutritional Supplement on the Healing of Chronic Wounds in Non-Malnourished Patients; A Multicenter Case Series from the Netherlands and Hungary. Journal of Gerontology and Geriatric Research, 6, 2. https://doi.org/10.4172/2167-7182.1000420

[22] Ye, J. and Mani, R. (2016) A Systematic Review and Meta-Analysis of Nutritional Supplementation in Chronic Lower Extremity Wounds. The International Journal of Lower Extremity Wounds, 15, 296-302.

https://doi.org/10.1177/1534734616674624

[23] McMahon, L., Tamary, H., Askin, M., Adams-Graves, P., Eberhardt, R.T., Sutton, M., et al. (2010) A Randomized Phase II Trial of Arginine Butyrate with Standard Local Therapy in Refractory Sickle Cell Leg Ulcers. British Journal of Haematology, 151, 516-524. https://doi.org/10.1111/j.1365-2141.2010.08395.x

[24] Wethers, D.L., Ramirez, G.M., Koshy, M., Steinberg, M.H., Phillips, G., Siegel, R.S., et al. (1994) Accelerated Healing of Chronic Sickle-Cell Leg Ulcers Treated with RGD Peptide Matrix. Blood, 84, 1775-1779. https://doi.org/10.1182/blood.V84.6.1775.bloodjournal8461775

[25] Quételet, A. (1871) Antropométrie ou mesure desdifférentes facultés de l'homme. C. Muquardt, Bruxelles.

[26] Pinheiro, A.B.V. (2004) Table for Assessing Food Consumption in Homemade Measures. Atheneu, Sao Paulo.

[27] World Health Organization (1995) Physical Status: The Use and Interpretation of Anthropometry. Genebra.

[28] Frisancho, A.R. (1981) New Norms of Upper Limb Fat and Muscle Areas for Assessment of Nutritional Status. The American Journal of Clinical Nutrition, 34, 2540-2545. https://doi.org/10.1093/ajcn/34.11.2540

[29] Blackburn, G.L. and Thornton, P.A. (1979) Nutritional Assessment of the Hospitalized Patients. Medical Clinics of North America, 63, 1103-1115. https://doi.org/10.1016/S0025-7125(16)31663-7

[30] Center for Studies and Research in Food (CSRF) (2011) Brazilian Food Composition Table. 4th Edition, UNICAMP, Campinas, $161 \mathrm{p}$.

[31] Brazilian Institute of Geography and Statistics (IBGE) (2011) 2008-2009 Household Budget Survey: Analysis of Personal Food Consumption in Brazil. IBGE, Rio de Janeiro.

[32] Harris, J.A. and Benedict, F.G. (1918) A Biometric Study of Human Basal Metabolism. Proceedings of the National Academy of Sciences of the United States of America, 4, 370-373. https://doi.org/10.1073/pnas.4.12.370

[33] Cereda, E., Klersy, C., Rondanelli, M. and Caccialanza, R. (2011) Energy Balance in Patients with Pressure Ulcers: A Systematic Review and Meta-Analysis of Observational Studies. Journal of the American Dietetic Association, 111, 1868-1876. https://doi.org/10.1016/j.jada.2011.09.005

[34] Institute of Medicine (IOM) (2005) Dietary Reference Intakes for Energy, Carbohydrate, Fiber, Fat, Fatty Acids, Cholesterol, Protein and Amino Acids (Macronutrients). The National Academies Pres, Washington DC.

[35] Leigh, B., Desneves, K., Rafferty, J., Pearce, L., King, S., Woodward, M.C., et al. (2012) The Effect of Different Doses of an Arginine-Containing Supplement on the Healing of Pressure Ulcers. Journal of Wound Care, 21, 150-156. https://doi.org/10.12968/jowc.2012.21.3.150

[36] National Pressure Ulcer Advisory Panel, European Pressure Ulcer Advisory Panel 
and Pan Pacific Pressure Injury Alliance (2014) Prevention and Treatment of Pressure Ulcers: Wound Care and Pain Management-An Extract from the Clinical Practice Guideline. Cambridge Media, Osborne Park.

[37] Benati, G., Delvecchio, S., Cilla, D. and Pedone, V. (2001) Impact on Pressure Ulcer Healing of an Arginine-Enriched Nutritional Solution in Patients with Severe Cognitive Impairment. Archives of Gerontology and Geriatrics, 33, 43-47. https://doi.org/10.1016/S0167-4943(01)00120-0

[38] Brewer, S., et al. (2010) Effect of an Arginine-Containing Nutritional Supplement on Pressure Ulcer Healing in Community Spinal Patients. Journal of Wound Care, 19, 311-316. https://doi.org/10.12968/jowc.2010.19.7.48905

[39] Institute of Medicine (IOM) (2006) Dietary Reference Intakes; the Essential Guide to Nutrients Requirements. National Academy Press, Washington DC.

[40] Otten, J.J., Hellwig, J.P. and Meyers, L.D. (2006) DRI, Dietary Reference Intakes: The Essential Guide to Nutrient Requirements. National Academies Press, Washington DC.

[41] Souza, K.C.M., Araújo, P.I.C., Souza-Junior, P.R.B. and Lacerda, E.M.A. (2011) Stunting and Wasting in Children and Adolescents with Sickle Cell Disease. Revista de Nutrição, 24, 853-862. https://doi.org/10.1590/S1415-52732011000600006

[42] Martyres, D.J., Vijenthira, A., Barrowman, N., Harris-Janz, S., Chretien, C. and Klaassen, R.J. (2016) Nutrient Insufficiencies/Deficiencies in Children with Sickle Cell Disease and Its Association with Increased Disease Severity: Nutrition Deficiencies in Childhood Sickle Cell Disease. Pediatric Blood \& Cancer, 63, 1060-1064. https://doi.org/10.1002/pbc.25940

[43] Reid, M. (2013) Nutrition and Sickle Cell Disease. Comptes Rendus Biologies, 336, 159-163. https://doi.org/10.1016/j.crvi.2012.09.007

[44] Olatunya, O.S., Albuquerque, D.M., Adekile, A.D. and Costa, F.F. (2018) Evaluation of Sociodemographic, Clinical, and Laboratory Markers of Sickle Leg Ulcers among Young Nigerians at a Tertiary Health Institution. Nigerian Journal of Clinical Practice, 21, 882 .

[45] Adams-Graves, P., Daniels, A.B., Womack, C.R. and Freire, A.X. (2014) Bone Mineral Density Patterns in Vitamin D Deficient African American Men with Sickle Cell Disease. The American Journal of the Medical Sciences, 347, 262-266. https://doi.org/10.1097/MAJ.0b013e3182893377

[46] Arlet, J.-B., Courbebaisse, M., Chatellier, G., Eladari, D., Souberbielle, J.-C., Friedlander, G., et al. (2013) Relationship between Vitamin D Deficiency and Bone Fragility in Sickle Cell Disease: A Cohort Study of 56 Adults. Bone, 52, 206-211. https://doi.org/10.1016/j.bone.2012.10.005

[47] Baldanzi, G., Traina, F., Francisco Marques Neto, J., Oliveira Santos, A., Dario Ramos, C. and Olalla Saad, S.T. (2011) Low Bone Mass Density Is Associated with Hemolysis in Brazilian Patients with Sickle Cell Disease. Clinics, 66, 801-805. https://doi.org/10.1590/S1807-59322011000500015

[48] McFarlane, I.M., Ozeri, D.J., Pathiparampil, J., Sanchez, R., Levinson, J., Barrett-Campbell, O., et al. (2017) Prevalence and Clinical Characteristics of Rheumatoid Arthritis in an Inner City Population with Sickle Cell Disease. Rheumatology (Sunnyvale, Calif.), 7, 218. https://doi.org/10.4172/2329-8731.1000218

[49] Souza, K.C.M., Damião, J.J., Siqueira, K.S., Santos, L.C.S. and Santos, M.R. (2008) Nutritional Follow-Up of Children with Sickle Cell Anemia Treated in a Primary Care Unit. Revista Paulista de Pediatria, 26, 400-404. https://doi.org/10.1590/S0103-05822008000400015 
[50] Verissimo, M.P.A. (2007) Growth and Development in Sickle Cell Disease. Revista Brasileira de Hematologia e Hemoterapia, 29, 271-274. https://doi.org/10.1590/S1516-84842007000300014

[51] Manci, E.A., Hyacinth, H.I., Capers, P.L., Archer, D.R., Pitts, S., Ghosh, S., et al. (2014) High Protein Diet Attenuates Histopathologic Organ Damage and Vascular Leakage in Transgenic Murine Model of Sickle Cell Anemia. Experimental Biology and Medicine, 239, 966-974. https://doi.org/10.1177/1535370214531863

[52] Hyacinth, H.I., Gee, B.E. and Hibbert, J.M. (2010) The Role of Nutrition in Sickle Cell Disease. Nutrition and Metabolic Insights, 3, NMI.S5048. https://doi.org/10.4137/NMI.S5048

[53] Institute of Medicine (2000) Dietary Reference Intakes for Vitamin C, Vitamin E, Selenium, and Carotenoids. National Academy Press, Washington DC.

[54] Marchioni, D.M.L., Slater, B. and Fisberg, R.M. (2004) Application of Dietary Reference Intakes to Assess Nutrient Intake for Individuals. Revista de Nutrição, 17, 207-216. https://doi.org/10.1590/S1415-52732004000200007

[55] Sobotka, L. (2008) Bases of Clinical Nutrition. Rubio, Rio de Janeiro.

[56] Porter, J. and Garbowski, M. (2013) Consequences and Management of Iron Overload in Sickle Cell Disease. Hematology, 2013, 447-456.

https://doi.org/10.1182/asheducation-2013.1.447

[57] Antwi-Boasiako, C., Dankwah, G., Aryee, R., Hayfron-Benjamin, C., Doku, A., N'guessan, B., et al. (2019) Serum Iron Levels and Copper-to-Zinc Ratio in Sickle Cell Disease. Medicina (Mex), 55, 180. https://doi.org/10.3390/medicina55050180

[58] Luiking, Y.C., Ten Have, G.A.M., Wolfe, R.R. and Deutz, N.E.P. (2012) Arginine de Novo and Nitric Oxide Production in Disease States. American Journal of Physiology-Endocrinology and Metabolism, 303, E1177-E1189. https://doi.org/10.1152/ajpendo.00284.2012

[59] Popolo, A., Adesso, S., Pinto, A., Autore, G. and Marzocco, S. (2014) L-Arginine and Its Metabolites in Kidney and Cardiovascular Disease. Amino Acids, 46, 2271-2286. https://doi.org/10.1007/s00726-014-1825-9

[60] Aliev, G., Palacios, H.H., Lipsitt, A.E., Fischbach, K., Lamb, B.T., Obrenovich, M.E., et al. (2009) Nitric Oxide as an Initiator of Brain Lesions during the Development of Alzheimer Disease. Neurotoxicity Research, 16, 293-305. https://doi.org/10.1007/s12640-009-9066-5

[61] Luiking, Y.C., Poeze, M., Ramsay, G. and Deutz, N.E. (2009) Reduced Citrulline Production in Sepsis Is Related to Diminished de Novo Arginine and Nitric Oxide Production. The American Journal of Clinical Nutrition, 89, 142-152. https://doi.org/10.3945/ajen.2007.25765

[62] Nakae, H., Endo, S., Kikuchi, M., Yamada, Y., Shibata, M., Ishikura, H., et al. (2000) Nitrite/Nitrate $\left(\mathrm{NO}_{x}\right)$ Levels and Hemodynamics during Septic Shock. Surgery Today, 30, 683-688. https://doi.org/10.1007/s005950070078

[63] Benites, B.D. and Olalla-Saad, S.T. (2019) An Update on Arginine in Sickle Cell Disease. Expert Review of Hematology, 12, 235-244. https://doi.org/10.1080/17474086.2019.1591948

[64] Cox, S.E., Ellins, E.A., Marealle, A.I., Newton, C.R., Soka, D., Sasi, P., et al. (2018) Ready-to-Use Food Supplement, with or without Arginine and Citrulline, with Daily Chloroquine in Tanzanian Children with Sickle-Cell Disease: A Double-Blind, Random Order Crossover Trial. The Lancet Haematology, 5, e147-e160. https://doi.org/10.1016/S2352-3026(18)30020-6 
[65] Shadvar, K., Sanaie, S., et al. (2018) Pressure Ulcer and Nutrition. Indian Journal of Critical Care Medicine, 22, 283-289. https://doi.org/10.4103/ijccm.IJCCM_277_17

[66] Park, J.-H., Kim, J.-Y., Kim, D.J., Kim, M., Chang, M., Chuck, R.S., et al. (2017) Effect of Nitric Oxide on Human Corneal Epithelial Cell Viability and Corneal Wound Healing. Scientific Reports, 7, Article No. 8093. https://doi.org/10.1038/s41598-017-08576-9

[67] Schwentker, A., Vodovotz, Y., Weller, R. and Billiar, T.R. (2002) Nitric Oxide and Wound Repair: Role of Cytokines? Nitric Oxide, 7, 1-10. https://doi.org/10.1016/S1089-8603(02)00002-2

[68] Heyman, H., Van De Looverbosch, D.E.J., Meijer, E.P. and Schols, J.M.G.A. (2008) Benefits of an Oral Nutritional Supplement on Pressure Ulcer Healing in LongTerm Care. Journal of Wound Care, 17, 476-480. https://doi.org/10.12968/jowc.2008.17.11.31475

[69] Cereda, E., Klersy, C., Serioli, M., Crespi, A. and D’Andrea, F. (2015) A Nutritional Formula Enriched with Arginine, Zinc, and Antioxidants for the Healing of Pressure Ulcers: A Randomized Trial. Annals of Internal Medicine, 162, 167. https://doi.org/10.7326/M14-0696

[70] Martins, A., Moreira, D.G., Nascimento, E.M. and Soares, E. (2013) Self-Care for the Treatment of Leg Ulcers in Sickle Cell Anemia: Nursing Guidelines. Escola Anna Nery-Revista de Enfermagem, 17, 755-763. https://doi.org/10.5935/1414-8145.20130021

[71] Kavalukas, S.L. and Barbul, A. (2011) Nutrition and Wound Healing: An Update. Plastic and Reconstructive Surgery, 127, 38S-43S. https://doi.org/10.1097/PRS.0b013e318201256c

[72] Keleidari, B., Mahmoudieh, M., Bahrami, F., et al. (2014) The Effect of Vitamin A and Vitamin C on Postoperative Adhesion Formation: A Rat Model Study. Journal of Research in Medical Sciences, 19, 28-32.

[73] Bottoni, A., et al. (2011) Role of Nutrition in Healing. Revista Ciências em Saúde, 1, 98-103. https://doi.org/10.21876/rcsfmit.v1i1.31

[74] Casey, G. (2003) Nutritional Support in Wound Healing. Nursing Standard, 17, 55-58. https://doi.org/10.7748/ns.17.23.55.s57

[75] Shepherd, A.A. (2003) Nutrition for Optimum Wound Healing. Nursing Standard, $18,55-58$. 